\title{
GÊNERO E SEXUALIDADE COMO COMPONENTES CURRICULARES NA FORMAÇÃO INICIAL DE PROFESSORAS DE CIÊNCIAS E BIOLOGIA DO RIO DE JANEIRO, RJ
}

\author{
GENDER AND SEXUALITY AS CURRICULAR COMPONENTS \\ IN THE INITIAL TRAINING OF SCIENCE AND BIOLOGY TEACHERS \\ IN RIO DE JANEIRO, RJ
GÉNERO Y SEXUALIDAD COMO COMPONENTES CURRICULARES EN LA FORMACIÓN INICIAL DE PROFESORES DE CIENCIA Y BIOLOGÍA EN RÍO DE JANEIRO, RJ

Raquel Alexandre Pinho dos Santos ${ }^{1}$

\begin{abstract}
Resumo
Esse artigo tem por objetivo compreender de que forma doze licenciaturas de Biologia na cidade do Rio de Janeiro (RJ) inserem os temas de gênero e sexualidade na sua estrutura curricular. Para isso, foi realizado um mapeamento dessas instituições e visitas para marcação de entrevistas com coordenadoras e professoras. Ao todo, foram realizadas dezesseis entrevistas. Além disso, alguns documentos curriculares serviram de apoio para a análise. Nas grades curriculares, foram encontradas quatro disciplinas obrigatórias que tangenciavam o tema e duas eletivas que tinham o tema como essência. Nas entrevistas, percebi que a inserção se dá por um gancho temático, por conflito de opiniões ou pela determinação da instituição. Não há consenso quanto a disciplinarização ou a transversalização do tema.
\end{abstract}

Palavras-chave: Formação docente; Licenciatura; Currículo; Gênero; Sexualidade.

\begin{abstract}
This paper aims to understand how twelve undergraduate biology teacher courses in the city of Rio de Janeiro (RJ) insert gender and sexuality themes on its curricula. To reach it, these instutions were mapped and visited to schedule interviews with teachers and coordinators. A total of sixteen interviews were conducted. Furthermore, some curriculary documents served as analysis support. The results were four mandatory disciplines that adressed the themes tanglently and two elective disciplines that adressed them essencially. On the interviews, it was noted that the insertion is made by thematic hooks, conflict of opinions or by intitutional demand. There is no consensus pertaining the disciplinarization or the transversalization of the theme.
\end{abstract}

Keywords: Teacher training; Graduation; Curriculum; Genre; Sexuality.

\footnotetext{
${ }^{1}$ Doutora em Educação - Pontifícia Universidade Católica do Rio de Janeiro (PUC-Rio). Gávea, RJ - Brasil. Pesquisadora Associada. Pontifícia Universidade Católica do Rio de Janeiro (PUC-Rio). Gávea, RJ - Brasil E-mail: $\underline{\text { raquel.ciencias@ gmail.com }}$
} 


\section{Resumen}

Ese artigo tiene por objetivo compreender de que forma doce cursos de pregado de Biología em la ciudad de Rio de Janeiro (RJ) insertan los temas de género y sexualidad en su estructura curricular. Para tanto, se realizó un mapeo de estas instituciones y visitas para programar entrevistas con coordinadores y docentes. En total, se realizaron dieciséis entrevistas. Además, algunos documentos curriculares sirvieron de soporte para el análisis. En las cuadrículas curriculares se encontraron cuatro disciplinas obligatorias que tocaron el tema y dos optativas que tuvieron el tema como esencia. En las entrevistas, me di cuenta de que la inserción se da a través de un gancho temático, conflicto de opiniones o por determinación de la institución. No hay consenso sobre disciplinar o transversalizar el tema.

Palabras clave: Formación de profesores; Graduación; Currículum; Género; Sexualidad.

$$
* * *
$$

\section{Introdução}

Esse artigo compõe minha tese de doutorado, intitulada "Resistências e emergências nas licenciaturas de Biologia: Discursos e práticas sobre sexualidade e gênero”, realizada de 2014 a 2018, cujo objetivo de pesquisa foi problematizar a formação inicial docente de Ciências e Biologia, para gênero e sexualidade, na cidade do Rio de Janeiro. Traduzido em questão, "Como as licenciaturas de Biologia da cidade do Rio de Janeiro buscam preparar as futuras docentes ${ }^{2}$ da educação básica para as questões de gênero e sexualidade?”.

Foi em meu segundo ano de doutoramento que essa temática de pesquisa ganhou força, em 2015, durante o IV Seminário Internacional de Educação Sexual - SIES, realizado na Universidade Estadual de Maringá (UEM). Assistindo aos trabalhos do encontro, notei que a maioria deles tratava da atuação docente, indicando que as professoras da Educação Básica não estão preparadas para trabalhar os temas de gênero e sexualidade em suas aulas. Eu, enquanto professora do segundo segmento do Ensino Fundamental da Educação Básica, me coloquei no lugar de todas aquelas professoras. Entendo que não é possível estar pronta, e que a formação inicial não dará conta de tudo que uma professora precisa; na experiência se aprende muito. Porém, a meu ver, havia uma lacuna na formação para o Ensino de Ciências e Biologia no que tange aos temas culturais.

Ali, nas cadeiras da UEM, me questionei: como são formadas essas professoras? Quais instrumentos teóricos e metodológicos que as formações iniciais conferem e que possibilitam trabalhar os temas de gênero e sexualidade na escola? Se existe formação continuada, ela continuaria o quê, se parece que pouco ou nada havia sido iniciado? Instigada por essas perguntas, voltei ao Rio de Janeiro com um problema de pesquisa a ser investigado. Para

\footnotetext{
2 A regra gramatical da língua portuguesa que define o masculino como elemento neutro em substantivos e adjetivos foi deliberadamente invertida para o feminino, independentemente do sexo dos sujeitos ao qual o termo se refere. Seguindo esta lógica, os substantivos e adjetivos usados no masculino neste texto ocorrem somente em referência específicas a sujeitos masculinos. "É, pra mim, estranho que pessoas sofisticadas em questões de poder, política e linguagem continuem isentando a gramática de qualquer cumplicidade na perpetuação de relações de desigualdade. (...) Apesar da dificuldade de lidar com essa questão em uma língua extremamente flexionada como o Português, continuo achando que vale a pena tentar encontrar soluções (N. do T.)" (ELLSWORTH, 2001, p. 75).
} 
DOI: http://doi.org/10.46667/renbio.v14i1.550

resolvê-lo, entrevistei coordenadoras e professoras dos doze cursos superiores de Licenciatura em Biologia, públicos e particulares, de regime presencial, tal como exponho a seguir.

\section{Procedimentos metodológicos}

Onde estão os cursos de licenciatura em Biologia na cidade do Rio de Janeiro? Quais as semelhanças e diferenças entre eles? Como tais cursos de licenciatura se estruturam? Como constroem o currículo? Como selecionam quais tópicos são relevantes para serem trabalhados na formação inicial? Gênero e sexualidade são tópicos considerados neste processo de seleção de conhecimento? E se selecionados, de que forma são abordados?

Para encontrá-los realizei um levantamento do site do Ministério da Educação ${ }^{3}$, resultando em dezoito cursos de ensino superior credenciados e ativos para a opção Ciências Biológicas, tanto públicos quanto privados, tanto presenciais quanto à distância, e oferecendo apenas licenciatura, apenas bacharelado ou ambos (Quadro 1). Destacados em negrito no Quadro 1, os doze cursos presenciais selecionados para esse estudo.

Uma vez que nem todos os cursos disponibilizavam informações específicas sobre os cursos em páginas de internet, realizei diversos contatos via ligações telefônicas, envios de emails e visitas aos locais a fim de obter informações sobre a grade curricular, as ementas e os Projetos Pedagógicos de Curso (PPC), assim como agendar as entrevistas com as coordenadoras. Essa etapa correspondeu a um investimento exaustivo de tempo.

O contato por telefone, que poderia agilizar o processo, não foi tão fácil como imaginei. Em geral, as ligações telefônicas culminavam em tentativas de vendas de matrículas em universidades particulares, desconfianças em passar informações a uma desconhecida ou simplesmente não sabiam dar informações a respeito da agenda e da disponibilidade das coordenadoras. $\mathrm{O}$ contato por e-mail também não trouxe grandes avanços, visto que muitas coordenadoras não responderam ao e-mail enviado e, dentre as que responderam, a resposta demorou. Certamente, há uma sobrecarga de tarefas a serem realizadas por essas coordenações, o que leva ao adiamento de tarefas não urgentes, como responder a e-mails de desconhecidas. Por outro lado, a espera para receber a resposta atrasou e angustiou o processo da pesquisa.

Sem êxito na comunicação à distância, realizei visitas às doze unidades escolhidas para iniciar o diálogo com o campo. Em nenhuma das muitas visitas realizadas tive a sorte da coordenadora do curso estar na unidade e estar disponível para realizar a entrevista de imediato. Em cada unidade, foram realizadas pelo menos quatro visitas: uma para conhecer a unidade e agendar a entrevista com a coordenadora, uma para realizar a entrevista com a coordenadora,

\footnotetext{
${ }^{3}$ http://emec.mec.gov.br/, acesso em 27/07/2016, às 18h01min.
} 
DOI: http://doi.org/10.46667/renbio.v14i1.550

uma para encontrar a professora indicada pela coordenação e agendar a entrevista, e outra para realizar a entrevista com a professora.

Para criar um ambiente de espontaneidade e confiança, optei por entrevistas semiestruturas (MANZINI, 2004). Das doze coordenações selecionadas, uma não foi entrevistada. Ela não recusou explicitamente a entrevista, mas não encontrou agenda para concedê-la. Pareceu-me resistente a dialogar com a pesquisa. Tal coordenação pediu que enviasse a pesquisa por e-mail, e ela responderia por escrito, mas optei por não fazer desta forma, uma vez que seria uma metodologia de obtenção de dados diferente e, por conseguinte, de comparação problemática com o restante dos dados, perdendo-se o componente rico da naturalidade das reações e relações traçadas em entrevistas presenciais (SARMENTO, 2003). 
DOI: http://doi.org/10.46667/renbio.v14i1.550

Quadro 1: Cursos de Ciências Biológicas ativos no município do Rio de Janeiro em 2016.

\begin{tabular}{|c|c|c|c|c|c|c|c|c|}
\hline Instituição & Sigla & Início $^{4}$ & Tipo & Modalidade & Curso & Período & Local & Duração \\
\hline Universidade Federal do Rio de Janeiro & UFRJ & 1931 & Pública Federal & Presencial/EAD & LIC/BAC & Integral/Noite & Ilha do Fundão & 4 anos \\
\hline Universidade Santa Úrsula & USU & 1957 & Privada & Presencial & LIC/BAC & Manhã & Botafogo & 3 anos \\
\hline Centro Universitário Augusto Motta & UNISUAM & 1968 & Privada & Presencial & LIC & Noite & Bonsucesso & 3 anos \\
\hline Faculdades Souza Marques & FSM & 1968 & Privada & Presencial & $\mathrm{LIC} / \mathrm{BAC}$ & Integral & Cascadura & 4 anos \\
\hline Universidade do Estado do Rio de Janeiro & UERJ & 1968 & Pública Estadual & Presencial/EAD & LIC/BAC & Integral & Maracanã & 4 anos \\
\hline Centro Universitário Celso Lisboa & UCL & 1976 & Privada & Presencial & $\mathrm{LIC} / \mathrm{BAC}$ & Manhã/Noite & Méier & 3 anos \\
\hline Universidade Veiga de Almeida & UVA & 1988 & Privada & Presencial & LIC/BAC & Tarde/Noite & Tijuca & 3 anos \\
\hline Universidade Castelo Branco & UCB & 1993 & Privada & Presencial/EAD & $\mathrm{LIC} / \mathrm{BAC}$ & Manhã/Noite & Realengo & 3 anos \\
\hline Universidade Estácio de Sá & UNESA & 2001 & Privada & Presencial & LIC/BAC & Noite & Taquara & 4 anos \\
\hline Faculdade São José & FSJ & 2002 & Privada & Presencial & $\mathrm{LIC} / \mathrm{BAC}$ & Noite & Realengo & 3 anos \\
\hline Universidade Federal do Estado do Rio de Janeiro & UNIRIO & 2006 & Pública Federal & Presencial & $\mathrm{LIC} / \mathrm{BAC}$ & Integral/Noite & Urca & 4 anos \\
\hline $\begin{array}{l}\text { Instituto Federal de Educação, Ciência e Tecnologia } \\
\text { do Rio de Janeiro }\end{array}$ & IFRJ & 2009 & $\begin{array}{l}\text { Pública } \\
\text { Federal }\end{array}$ & Presencial & BAC & Tarde & Maracanã & 4 anos \\
\hline Centro Universitário Hermínio da Silveira & IBMR & 2010 & Privada & Presencial & BAC & Manhã/Noite & Catete & 4 anos \\
\hline Universidade Norte do Paraná & UNOPAR & 2012 & Privada & EAD & LIC & - & - & 3,5 anos \\
\hline Universidade Luterana do Brasil & ULBRA & 2014 & Privada & EAD & LIC & - & - & 4 anos \\
\hline Universidade Paulista & UNIP & 2014 & Privada & EAD & LIC & - & - & 3 anos \\
\hline Centro Universitário Estadual da Zona Oeste & UEZO & 2015 & Pública Estadual & Presencial & BAC & Integral & Campo Grande & 4 anos \\
\hline Pontifícia Universidade Católica do Rio de Janeiro & PUC-Rio & 2016 & Privada & Presencial & $\mathrm{LIC} / \mathrm{BAC}$ & Integral & Gávea & 4 anos \\
\hline
\end{tabular}

Fonte: Elaboração própria.

\footnotetext{
${ }^{4}$ Início do curso de licenciatura.
} 
DOI: http://doi.org/10.46667/renbio.v14i1.550

Nas entrevistas com as coordenadoras, pedi indicação de uma docente que trabalhasse com temas afins aos de gênero e sexualidade. Das onze coordenadoras entrevistadas, quatro não indicaram professoras, seis indicaram uma professora, e apenas uma coordenadora indicou mais de uma professora. Ao total, realizei dezesseis entrevistas, que compuseram 17h32min de material de áudio e que resultou em 281 páginas de transcrições, analisadas com o auxílio do software Atlas ti.

Nas entrevistas com as coordenadoras, estava previsto um bloco de questões sobre a organização do curso: "Fale-me um pouco da organização curricular do curso. Quando foi construído? Tem algum documento que orienta o curso? O que é mais característico no currículo da sua instituição?’. Nas respostas às questões, recebi informações dos documentos consultados por elas, da grade curricular e do PPC. No PPC, deveriam constar todas as unidades curriculares, com suas cargas horárias e competências, perfil profissional da egressa, história do curso, além de outros itens, segundo o qual o curso será desenvolvido. Minha intenção era triangular as entrevistas com os documentos dos cursos, buscando identificar os temas de gênero e sexualidade no currículo, assim como se a instituição prioriza uma formação pensada em e para a diversidade.

Entretanto, os PPC disponibilizados apenas auxiliaram como dados enriquecedores para a pesquisa, mas não foi possível realizar uma análise sistemática desses documentos. Devido ao momento das licenciaturas, que à época passavam por uma reforma curricular a partir das diretrizes CNE/CES 02/2015 (BRASIL, 2015), as coordenadoras preferiram não compartilhar os PPC vigentes ou em construção. Todas as entrevistadas indicaram que o curso estava passando por uma reformulação e que enviariam por e-mail tanto os documentos usados à época das entrevistas, quanto os reformulados posteriormente. Infelizmente, não tive acesso a tal documentação ${ }^{5}$. Apenas duas instituições me enviaram prontamente suas grades curriculares e PPC. Recorri, então, aos sites institucionais dos cursos. Neles, encontrei a maioria das grades curriculares e um ementário disponível, os quais utilizei para pensar os temas presentes na formação inicial. Destaco que tais documentos se referem ao currículo ativo em 2016.

\footnotetext{
${ }^{5}$ Como sugestão para outras pesquisadoras da área, indico que utilizem o tempo de visitas ao campo para obter toda documentação necessária, sem esperar que isso seja feito em momento posterior via e-mail. Por mais que a tecnologia nos facilite e nos aproxime, o tempo é um recurso escasso para a pesquisa e precisa ser muito bem aproveitado.
} 
DOI: http://doi.org/10.46667/renbio.v14i1.550

\section{Quem é a formação inicial em Ciências e Biologia?}

Apresento aqui as informações obtidas nas entrevistas. No Quadro 2, trago um apanhado de características curriculares que estruturam os cursos: carga horária, número de períodos, disciplinas obrigatórias e eletivas, atividades complementares, momento em que se iniciam as disciplinas pedagógicas e estágio. Quanto à organização das disciplinas, observo três perfis de curso: (i) presença de um ciclo básico, unificando bacharelado e licenciatura e depois separa; (ii) cursos de bacharelado e licenciatura separados desde o início com matérias em comum; e (iii) curso independente, pois nesta instituição não tem bacharelado.

Quadro 2: Informações curriculares dos cursos de licenciatura em Biologia no ano de 2016.

\begin{tabular}{|c|c|c|c|c|c|c|c|c|c|c|}
\hline \multirow[b]{3}{*}{ 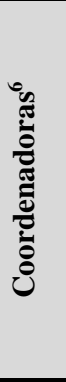 } & \multirow[b]{3}{*}{ 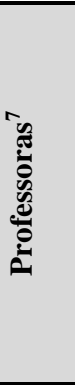 } & \multicolumn{9}{|c|}{ Estrutura curricular } \\
\hline & & \multirow[b]{2}{*}{ 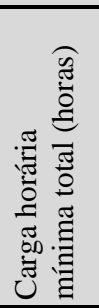 } & \multirow[b]{2}{*}{ 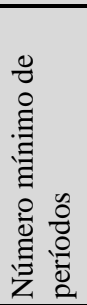 } & \multirow[b]{2}{*}{ 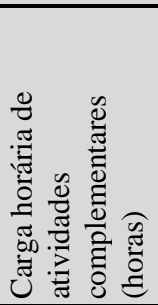 } & \multicolumn{3}{|c|}{ Disciplinas } & \multicolumn{3}{|c|}{ Estágio } \\
\hline & & & & & 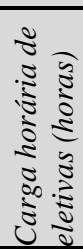 & 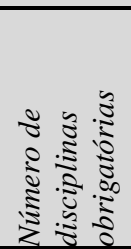 & 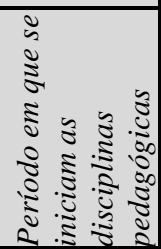 & 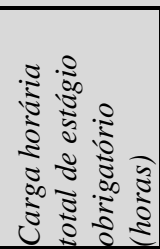 & 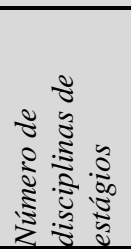 & 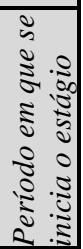 \\
\hline C1 & & 3.495 & 8 & 210 & 390 & 42 & $3^{\circ}$ & 420 & 4 & $5^{\circ}$ \\
\hline $\mathbf{C 2}$ & & 3.200 & 7 & 200 & 160 & 41 & $3^{\circ}$ & 400 & 3 & $5^{\circ}$ \\
\hline $\mathbf{C 3}$ & $\mathbf{P 3}$ & 3.762 & 6 & 200 & & 39 & $1^{\circ}$ & & 3 & $4^{\circ}$ \\
\hline $\mathbf{C 4}$ & $\mathbf{P 4}$ & 3.485 & 8 & 200 & 390 & 47 & $2^{\circ}$ & 420 & 6 & $5^{\circ}$ \\
\hline $\mathbf{C 5}$ & P5 & 3.075 & 8 & 200 & 60 & 49 & $1^{\circ}$ & 400 & 1 & $8^{\circ}$ \\
\hline C6 & & 3.645 & 8 & 210 & 180 & 42 & $3^{\circ}$ & 420 & 2 & $7^{\circ}$ \\
\hline $\mathbf{C 7}$ & P7 & 3.465 & 8 & 200 & 90 & 40 & $5^{\circ}$ & 400 & 2 & $7^{\circ}$ \\
\hline $\mathbf{C 8}$ & P8 & 3.120 & 6 & 200 & & 35 & $1^{\circ}$ & 440 & 2 & $5^{\circ}$ \\
\hline C9 & & & 6 & & & & & 400 & 2 & \\
\hline C10 & & 3.337 & 6 & 200 & 40 & 38 & $1^{\circ}$ & 400 & 3 & $5^{\circ}$ \\
\hline$\overline{C 11}$ & & 3.220 & 6 & 200 & & 46 & $1^{\mathrm{o}}$ & 400 & 2 & $5^{\circ}$ \\
\hline $\mathrm{C} 12$ & & 2.824 & 6 & 200 & & 38 & $3^{\circ}$ & 400 & 2 & $5^{\circ}$ \\
\hline
\end{tabular}

Fonte: Elaboração própria

\footnotetext{
${ }^{6}$ Para manter o anonimato, as coordenadoras foram identificadas pela letra $\mathrm{C}$ e numeradas de 1 a 12 .

${ }^{7}$ Para manter o anonimato, as professoras foram identificadas pela letra $\mathrm{P}$ e numeradas de 1 a 8.
} 
DOI: http://doi.org/10.46667/renbio.v14i1.550

Quanto à lógica epistemológica das disciplinas, distingo dois perfis de curso: fragmentação e integralidade. Alguns cursos trazem de maneira fragmentada os conhecimentos específicos, tanto disciplinares quanto pedagógicos. Por exemplo, observamos na grade curricular disciplinas separadas e sequenciadas: anatomia, histologia e fisiologia, indicando um recorte tradicional do conhecimento. Em outros cursos, observamos um movimento pela integralidade substituindo a descrição recortada. Fragmentada ou integralizada, a formação ainda está centrada no conhecimento disciplinar. Maurice Tardif (2014) nos alerta que o magistério ao ser idealizado em um modelo aplicacionista do conhecimento traz limitações para a formação profissional: o perigo de as disciplinas não terem relação entre si; o foco no conhecimento e não na ação; não considerar experiências e representações das licenciandas a respeito do ensino.

A perspectiva integralizada parece ancorada em uma aposta na interdisciplinaridade. Ao priorizar a relação entre diferentes campos de conhecimento, tanto as subáreas da Biologia e da Pedagogia são tratadas de forma integralizada, quanto outros campos de saber são chamados ao diálogo. Observei nessas instituições interdisciplinaridade com o Direito, a Sociologia, a Engenharia e a Letras. Porém, a licenciatura em Biologia já é em essência interdisciplinar, uma vez que é formada pelos campos da Pedagogia e da Biologia. Durante a formação, está presente a biologia geral, a pedagogia geral e o "ensinar Biologia". Algumas entrevistadas indicam a necessidade de se aprofundar esta relação interdisciplinar, aprofundar os conhecimentos didáticos específicos, qualificando a formação. Isso nos aponta para a lacuna existente nas formações de professoras que precisar ensina, para qual seja o tema, estratégias de ensinoaprendizagem. Além de discutir temas de gênero e sexualidade, de que forma nossas licenciandas aprendem a trabalhar esses temas na escola? Que ferramentas oferecemos a elas para colocarem em prática esse saber?

C4: A gente dá a mesma anatomia pro curso de licenciatura e pro curso de bacharelado, o mesmo conteúdo, mas você acaba que você não ensina ao licenciando a ensinar anatomia lá dentro da escola. Então, não seria legal ter uma disciplina completamente separada de anatomia, onde você vai ensinar ao licenciando a realmente ensinar anatomia? $O$ que ele pode estar usando como prática com um pequenininho, que não entende.

Quanto à prática pedagógica, existem disciplinas direcionadas para a reflexão da vivência escolar e o estágio propriamente dito, no qual são realizadas atividades de observação e/ou de regência. Os estágios aparecem de três formas: em colégios de aplicação da instituição, credenciados ou escolhidos pelas licenciandas sem lista prévia. Os estágios podem acontecer com supervisão docente, no qual a licencianda tem um tempo alocado em uma disciplina para discussão das vivencias no estágio, e sem supervisão docente, no qual é controlado pela coordenação, sem um tempo disciplinar específico. O momento do estágio é muito variado. Mesmo tendo uma professora responsável pela turma de estágio, ela pode se reunir semanalmente com a turma ou não, ela pode visitar a escola ou não, ela pode manter contato com a professora regente na escola ou não, ela pode assistir à regência da licencianda ou não. Enfim, este é um momento muito particular da formação e que, portanto, está fortemente 
DOI: http://doi.org/10.46667/renbio.v14i1.550

atrelado à identidade do curso e, consequentemente, à identidade profissional das licenciandas formadas por ela. $\mathrm{O}$ momento do estágio pode ser um espaço de emergência da discussão dos temas de gênero e sexualidade, contudo isso não aparece de maneira evidente nos relatos.

Além do estágio, outras características emergem como diferenciais dos cursos. Ao serem perguntadas sobre "Qual o diferencial do currículo do curso? O que é mais característico do currículo da sua instituição?”, as coordenadoras indicam as qualidades abaixo listadas.

- C1: diálogo, encontro, experiências interpessoais, proximidade/afetividade, espaço moderno

- C2: proximidade/afetividade, metodologia moderna, educação científica

- C3: curso descentralizado, autonomia docente

- C4: priorizar a formação da bióloga, curso grande com muitos departamentos

- C5: atualização curricular

- C6: priorizar a formação da bióloga, curso amarrado

- C7: proximidade/afetividade

- C8: presença de um ranário na instituição

- C9: saídas de campo, viés ecológico

- C10: saídas de campo, proximidade/afetividade, prática pedagógica desde o primeiro período

- C11: proximidade/afetividade, prática pedagógica desde o primeiro período, programas de extensão voltados para a docência

Destaco que outras características dos cursos foram percebidas ao longo das entrevistas. Porém, as indicações acima dizem da resposta direta à pergunta sobre uma característica marcada do curso. É aquilo que as coordenadoras ativamente destacaram e que emergiu no momento da resposta. Estão presentes características que marcam a formação em Ciências Biológicas: priorização de temas disciplinares, laboratórios e saídas de campo, em contraste com características de formação pedagógica: prática pedagógica desde o primeiro período, extensão para a docência e educação científica. Observe que há uma valorização da proximidade e da afetividade que o curso tenta construir com suas alunas, aparecendo em cinco respostas. Indico, portanto, que as relações interpessoais são um qualificador do espaço formativo. Dessa forma, entendo que conhecer a formação inicial é conhecer quem as organiza, pratica e gerencia. 


\section{Como gênero e sexualidade aparecem nessa estrutura curricular?}

Gênero e sexualidade não se constituem como temas consolidados em disciplinas formais. A partir dos dados gerados nas entrevistas com as coordenadoras e professoras, percebo que essas formações se dão por resistências e recentes emergências. Entendo resistência como explica Michel Foucault (2009, 2012a): um contraponto nas relações de poder. Para ele, se não houver possibilidade de resistência, não há de forma alguma relação de poder. $\mathrm{Ou}$ seja, por mais desequilibrada que seja a situação, se houver liberdade, se houver possibilidade de resistência, haverá diferentes possibilidades de resultados.

Isso nos leva ao problema do que entendo por poder. [...] quando se fala de poder, as pessoas pensam imediatamente em uma estrutura política, em um governo, em uma classe social dominante, no senhor diante do escravo etc. Não é absolutamente o que penso quando falo das relações de poder. Quero dizer que nas relações humanas, quaisquer que sejam elas, [...] o poder está presente, a relação em que uma procura dirigir a conduta da outra. [...] Essas relações de poder são, portanto, móveis, reversíveis e instáveis. Certamente também é preciso enfatizar que só é possível haver relações de poder quando os sujeitos forem livres. [...] Isso significa que, nas relações de poder, há necessariamente possibilidade de se resistência, pois se não houvesse possibilidade de resistência - de resistência violenta, de fuga, de subterfúgios, de estratégias que invertam a situação -, não haveria de forma alguma relações de poder". (FOUCAULT, 2012a, p. 270)

"A resistência é a possibilidade de criar espaços de lutas e de agenciar possibilidades de transformação em toda parte" (REVEL, 2005, p. 74). Assim parece que, por mais que haja dificuldades no enfrentamento dos temas de gênero e sexualidade nas formações, alguns espaços optam por incluí-los em suas grades e algumas professoras optam por incluí-los em suas práticas, o que configura resistência, um contraponto em relação a outros discursos fortemente estabelecidos na sociedade e na academia.

Importa destacar que, ao pensar na institucionalização, também olho para novos tipos de controle destes temas e das sujeitas. "É a aparição ou antes a especificação institucional e como que o batismo de um novo tipo de controle - ao mesmo tempo conhecimento e poder sobre os indivíduos que resistem à normalização disciplinar" (FOUCAULT, 2008, p. 245). Isso porque as disciplinas e a emergência de biopoderes se aplicam ao mesmo tempo às indivíduas em sua existência singular e às populações segundo o princípio da economia e da gestão política. A aparição de tecnologias do comportamento forma, portanto, uma configuração do poder (FOUCAULT, 2008). Assim, a formação é investimento em subjetividade e poder. Quando as disciplinas voltadas para as discussões de sexualidade e gênero surgem nas grades curriculares da formação? E sob que condições? Que nomes recebem? Que discursos as autorizam? E quais as constrangem? Em que investem? Para auxiliar a pensar nessas perguntas, trago uma conceituação sobre as emergências: 
DOI: http://doi.org/10.46667/renbio.v14i1.550

emergência (do lat. emergere: mergulhar) Termo utilizado pelos filósofos para designar o fato de um fenômeno brotar de um outro, não podendo ser analisado em termos de explicação causal. Assim, um fenômeno é denominado emergente quando é impossível, a partir das leis disponíveis no momento, fornecer-lhe uma explicação causal. Por isso, a emergência se reduz a uma constatação, sendo relativa a um estado histórico do desenvolvimento das ciências. (JAPIASSÚ; MARCONDES, 2006, p. 83)

Emergência, ou condições de emergência, é um tópico amplamente explorado por Michel Foucault ao longo de sua obra (2014, 2012a, 2012b, 2008). "Às vezes, Foucault utiliza igualmente o termo veridicção a fim de designar essa emergência de formas que permitem aos discursos, qualificados de verdadeiros em função de certos critérios, articularem-se com um certo domínio de coisas" (REVEL, 2005, p. 87). Emergência, aparecimento, aparição, enunciação são ideias relacionadas à ruptura de um processo, de uma descontinuidade paradigmática.

A positividade de um discurso caracteriza a sua unidade através do tempo. [...] Assim, a positividade desempenha o papel daquilo a que poderíamos chamar um a priori histórico, [...] que seria não condição de validade de juízos, mas condição de realidade de enunciados. Não se trata de descobrir o que poderia tornar legítima uma asserção, mas de isolar as condições de emergência dos enunciados, a lei da sua coexistência com outros, a forma específica do seu modo de ser, os princípios segundo os quais subsistem, se transformam e desaparecem. (FOUCAULT, 2014, p. 174-176)

Pensar sobre as emergências disciplinares nesse trabalho foi um movimento inspirado na arqueologia foucaultiana, que visa compreender as condições de emergência dos discursos de saber de uma dada época, isto é, de que forma saberes locais se determinaram e se relacionaram constituindo novos objetos, que visa compreender o presente. "Se eu faço isso, é com o objetivo de saber o que nós somos hoje" (FOUCAULT, 2012b, p. 258).

Ao tratar de emergências disciplinares, indico o aparecimento de disciplinas ou práticas disciplinares para as questões de sexualidade e gênero no cotidiano da formação, o que é tratar de um espaço de produção de subjetividade, um espaço de biopolítica, um espaço potente de constituição ética das sujeitas. As disciplinas não são a emergência dos discursos sobre sexualidade e gênero na formação. Os discursos já estão presentes há muito, nos corredores, nas conversas entre as alunas, nos movimentos estudantis. Mas ao incluí-los em planejamentos e práticas curriculares, ocorre a institucionalização destes temas. É dessa emergência institucional que falo aqui. O que é discurso oficializado da formação? E o que não é? E por que essa separação? Quem separa o que cabe e o que não cabe à formação? A verdade é produzida pelo e no discurso. $\mathrm{E}$ os regimes de verdade podem mudar se mudarem as regras de formação dos discursos que portam as verdades. 
DOI: http://doi.org/10.46667/renbio.v14i1.550

Gênero e sexualidade são temas atuais, estão presentes nos noticiários de maneira recorrente, seja sobre estudos de casos das identidades na fronteira, seja sobre inúmeros exemplos de preconceito, discriminação ou violência motivos por esse componente identitário, inclusive em espaços escolares e universitários. Por mais que seja um assunto em pauta na sociedade, as coordenadoras indicaram que a emergência destas disciplinas se dá através das resoluções oficiais. Sem isso, elas disseram, nada mudaria. Seriam os temas de gênero e sexualidade vistos como menos científicos e, por isso, menos presentes nesses espaços de formação?

E: Uma última pergunta que eu não tenho certeza se eu fiz. Você falou que não tem a disciplina e que não pretende que tenha uma disciplina relacionada a isso. Isso é uma escolha do curso? Por que não é uma demanda?

C3: Eu acho que é porque a construção do curso é sempre muito voltada pra uma questão técnica, né? Pra você criar um currículo que atenda as exigências do Conselho Nacional de Educação, que abranja a maior quantidade de temas possivel para formar generalistas. Então, talvez se tivesse nessa resolução como tem "Você tem que ter Filosofia, você tem que ter Sociologia" [...] Se houver alguma exigência, ai eu acho que ai sim. Alguém pensaria em falar sobre isso. Pensaria em propor uma disciplina pra falar sobre isso. Mas enquanto não houver essa determinação, eu acho isso pouco provável.

$\boldsymbol{E}$ : Então, você acha que pra essa conversa acontecer na unidade, ela vem de cima pra baixo?

C3: Com certeza.

E: Não tem nenhuma disciplina de saúde?

C6: Tem uma de saúde ambiental, ou saúde do meio ambiente, eu sempre confundo as duas, porque uma é de um curso, e a outra é de outro, e eu não sei se dá alguma coisa disso.

E: Professor da parte de embriologia? De anatomia? Também não entra nessas questões?

C6: Não, de sexualidade nem pensar.

E: E essa disciplina de multiculturalismo que vai entrar? Ela já existe?

C6: Ela existe no papel, no curso não, mas ela existe na universidade, ela foi criada para atender essa normativa do MEC.

$\boldsymbol{E}:$ Aqui não tem perspectiva?

C7: Não tem perspectiva ainda não, só que isso é uma orientação obrigatória do governo, e a gente vai ter que cumprir.

No Quadro 3, trago as declarações e indicações sobre os temas de gênero e sexualidade no currículo. Das doze instituições, quatro afirmaram que o tema está presente no curso, porém apenas três indicaram professoras para a entrevista, todas disciplinas são eletivas e oscilantes em oferta (não abre todos os períodos). Das doze instituições, oito não apontaram o tema no currículo. Todavia, ainda que na incerteza, quatro delas indicaram professoras para a entrevista, 
DOI: http://doi.org/10.46667/renbio.v14i1.550

todas de disciplinas obrigatórias. No total, foram sete professoras indicadas. Cinco aceitaram conversar comigo.

Quadro 3: Informações curriculares dos cursos de licenciatura em Biologia no ano de 2016.

\begin{tabular}{|c|c|c|c|c|c|c|c|}
\hline \multirow[b]{2}{*}{ 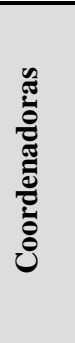 } & \multirow[b]{2}{*}{ 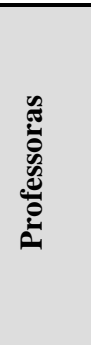 } & \multicolumn{6}{|c|}{ Gênero e Sexualidade } \\
\hline & & 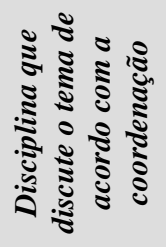 & 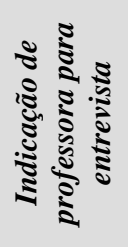 & $\begin{array}{l}\text { Nome da disciplina } \\
\text { indicada }\end{array}$ & 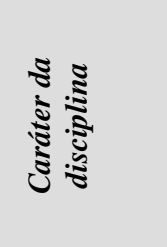 & 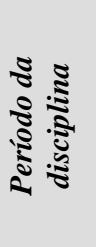 & 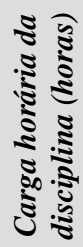 \\
\hline C1 & & Não & Não & & & & \\
\hline $\mathbf{C 2}$ & & Não & Sim & Antropologia cultural & Obrigatória & $3^{\circ}$ & 40 \\
\hline $\mathbf{C 3}$ & $\mathbf{P 3}$ & Não & Sim & $\begin{array}{l}\text { Aspectos antropológicos e sociológicos } \\
\text { da educação }\end{array}$ & Obrigatória & $2^{\circ}$ & 66 \\
\hline $\mathbf{C 4}$ & $\mathbf{P 4}$ & Sim & Sim & Sexualidade humana & Eletiva & & 45 \\
\hline $\mathbf{C 5}$ & $\mathbf{P 5}$ & Não & Sim & Multiculturalismo e movimentos sociais & Obrigatória & $7^{\circ}$ & 30 \\
\hline C6 & & Não & Não & & & & \\
\hline $\mathbf{C 7}$ & P7 & Sim & Sim & Educação e Gênero & Eletiva & & 45 \\
\hline $\mathbf{C 8}$ & P8 & Não & Sim & Práticas pedagógicas & Obrigatória & $8^{\circ}$ & 100 \\
\hline C9 & & Não & Não & & & & \\
\hline C10 & & Sim & Não & & & & \\
\hline C11 & & Sim & Sim & Saúde ambiental & Eletiva & & 40 \\
\hline $\mathbf{C 1 2}$ & & \multicolumn{6}{|c|}{ Não realizou a entrevista. } \\
\hline
\end{tabular}

Fonte: Elaboração própria.

Desse apanhado, duas são disciplinas temáticas. A disciplina Educação e Gênero entrou para o currículo em 2008 e tem sido regularmente oferecida. Sobre ela, a professora indicou:

P7: Na Educação e Gênero, eu já tinha um incômodo, que é o fato do que a gente opera. Primeiro, eu tenho o incômodo de dar uma disciplina sobre gênero e sexualidade, não tenho muito consenso comigo mesmo de que isso deveria ser uma disciplina obrigatória nos cursos de graduação, tenho uma certa resistência a achar que deveria ser obrigatória, certamente porque vira de alguém, ela vira um terreno. 
DOI: http://doi.org/10.46667/renbio.v14i1.550

A disciplina Sexualidade humana entrou para o currículo há mais de uma década, mas passou muito tempo parada, tendo sido reativada no fim de 2016. A entrevistada diz que não foi ela quem criou a eletiva. No relato de P7 e P4, tais temas podem se tornar terrenos, seja no ímpeto de controle por parte de quem ocupa sua docência, seja pela ausência de quem a ocupe quando a professora regular se aposenta ou afasta da instituição, deixando a disciplina vaga por longos períodos. Como vemos no Quadro 4, não houve consenso quanto a disciplinarizar o tema, e menos ainda quanto a torná-lo obrigatório.

Quadro 4: Sobre disciplinarizar os temas de gênero e sexualidade na formação.

\begin{tabular}{|c|c|c|c|}
\hline & $\begin{array}{l}\text { Como o } \\
\text { tema } \\
\text { aparece? }\end{array}$ & O tema está na grade? & Deve estar? \\
\hline C1 & $\begin{array}{l}\text { "Não é uma } \\
\text { questão" }\end{array}$ & Transversalizado & Não \\
\hline $\mathbf{C 2}$ & $\begin{array}{l}\text { Não aparece } \\
\text { | Conflito }\end{array}$ & Indica 1 disciplina que talvez trabalhe & \\
\hline C3 & $\begin{array}{l}\text { Não aparece } \\
\text { | Conflito }\end{array}$ & Indica 1 disciplina que talvez trabalhe & Não \\
\hline C4 & Instituição & Nem sempre, é eletiva. & Sim \\
\hline C5 & Gancho & Indica 1 disciplina que talvez trabalhe & \\
\hline C6 & Conflito & Não & Não \\
\hline C7 & Instituição & Nem sempre, é eletiva & Sim \\
\hline C8 & Instituição & Indica 1 disciplina que talvez trabalhe & Não \\
\hline C9 & Não aparece & Não & \\
\hline C10 & Gancho & Transversalizado & Sim \\
\hline C11 & $\begin{array}{l}\text { Não aparece } \\
\text { | Gancho }\end{array}$ & Indica 1 disciplina que talvez trabalhe & \\
\hline $\mathbf{P 3}$ & Gancho & $\begin{array}{l}\text { "na disciplina que eu ensino, que é de } \\
\text { Ciências Sociais e Educação, ele seria } \\
\text { pontual realmente, seria pontual, em } \\
\text { algum momento se colocaria a } \\
\text { discussão" }\end{array}$ & $\begin{array}{l}\text { "Porque o nosso debate ocidental, ela é } \\
\text { transversal o tempo todo. Eu acho que isso é } \\
\text { um alinhamento que nós não superamos } \\
\text { ainda, e talvez não devamos superar" }\end{array}$ \\
\hline $\mathbf{P 4}$ & $\begin{array}{l}\text { Instituição | } \\
\text { Alunas }\end{array}$ & $\begin{array}{l}\text { Sim, em uma disciplina eletiva. Mas } \\
\text { sua oferta depende de uma professora } \\
\text { se disponibilizar. }\end{array}$ & $\begin{array}{l}\text { "No nível de graduação, ele deveria ser uma } \\
\text { disciplina em separado, porque aí você tem } \\
\text { mais tempo para trabalhar os conceitos e } \\
\text { apresentar recursos para o aluno que vai ser } \\
\text { professor depois trabalhar." }\end{array}$ \\
\hline P5 & Gancho & $\begin{array}{l}\text { "Apesar de o foco ser outro, esse tema } \\
\text { aparece, muitas vezes os alunos falam" }\end{array}$ & $\begin{array}{l}\text { "Sem dúvida. Eu acho que deveria estar } \\
\text { explícita na lei" }\end{array}$ \\
\hline P7 & $\begin{array}{l}\text { Instituição } \\
\text { Gancho }\end{array}$ & $\begin{array}{l}\text { Sim, em uma disciplina eletiva } \\
\text { específica, mas também inserido em } \\
\text { uma disciplina obrigatória de didática. }\end{array}$ & $\begin{array}{l}\text { "Não tenho muito consenso comigo mesmo } \\
\text { de que isso deveria ser uma disciplina } \\
\text { obrigatória nos cursos de graduação" }\end{array}$ \\
\hline $\mathbf{P 8}$ & Gancho & $\begin{array}{l}\text { "Ele aparece porque ele vai aparecer } \\
\text { nos próprios PCN" }\end{array}$ & $\begin{array}{l}\text { "Eu acho que são temas que tem que ser } \\
\text { incorporados" }\end{array}$ \\
\hline
\end{tabular}

Fonte: Elaboração própria. 
DOI: http://doi.org/10.46667/renbio.v14i1.550

Felipe Bastos (2015, p. 129) nos apresenta três caminhos para compreender a inserção dos temas de gênero e sexualidade nas aulas de professoras da Educação Básica entrevistadas em sua pesquisa de mestrado: (1) conflito; (2) ação isolada; e (3) gancho. Ao analisar a fala das entrevistadas aqui, usei a classificação construída por Felipe Bastos. No Quadro 4, apontei esses caminhos e apresentei um quarto: (4) por um pedido da instituição.

Não parece estar presente a ação isolada, que Felipe Bastos (2015, p. 133) descreve como "um sentimento de que [...] suas práticas não dialogam com o pensamento geral da escola, reiterado pela percepção tanto da homofobia quanto da constante polêmica levantada pelo assunto", um sentido de "que suas práticas se estabelecem para fora do escopo de práticas legitimadas tanto pela escola quanto [...] pelo currículo das disciplinas escolares Ciências e Biologia". Muito provavelmente, isso se deve ao desenho da pesquisa realizada. Uma vez que contornei o campo a partir das coordenações, elas só poderiam indicar professoras que trabalhavam com o tema a partir do aval da instituição. É provável que nas licenciaturas onde não se declara o trabalho com o tema, existissem professoras que incorporavam tais discussões às suas práticas. Mas para encontrá-las eu teria de ter feito outro caminho, por exemplo, iniciando o levantamento com as licenciandas.

Quando o tema aparece no currículo a partir de um gancho com outros temas já previstos, assumi que os conhecimentos estabelecidos no currículo "não existem isolados de outros conhecimentos e podem servir de apoio para legitimar outros saberes" (BASTOS, 2015, p. 140).

\section{E: Esses temas aparecem na formação do professor de Biologia?}

C11: Olha, não.

$\boldsymbol{E}:$ Nem dentro de uma disciplina?

C11: A gente tem modelo, a gente tem uma disciplina em EAD, que acho que ainda está muito incipiente, tem muita coisa para crescer, ela fala sobre ética, cidadania, ela pode abordar também o gênero.

As coordenadoras falaram do gancho que pode ser realizado pelas professoras. Porém, ao conversar com as professoras, observei que elas preparavam o terreno para que o gancho acontecesse, mas quem o realizava eram as próprias turmas. No caso do gancho, as professoras conferiram condições para que a discussão no tema emergisse. A professora P8 indicou que sua disciplina é sobre as práticas pedagógicas. Ela construía a disciplina a partir do estudo dos PCN. As alunas precisavam preparar uma atividade e aplicar para exercício metodológico. Como o tema está presente nos PCN, aparecia em algumas atividades e ganhava espaço para discussão. Inclusive, em momento posterior, P8 declara a potencialidade de se aproveitar o tema da aula para desenvolver outros assuntos, como gênero e sexualidade. 
DOI: http://doi.org/10.46667/renbio.v14i1.550

P8: Ele aparece porque ele vai aparecer nos próprios PCN. Você já tem alguma questão dessa nos próprios PCN. Agora, eu não discuto diretamente esses temas com eles, porque as aulas são abertas, eles escolhem um tema, me entende? "Ah, vamos dar uma aula sobre a célula", "Tudo bem". Outro sobre meio ambiente... o tema é deles.

P8: Eu acho que o professor, muitas vezes se tem a ideia de que, se o professor não fala do tema estrito da sala de aula, ele perdeu tempo. Eu falo para os meus alunos que não é assim não.

O professor P5 indicou que sua disciplina é sobre multiculturalismo e movimentos sociais. Apesar de ser focado em movimentos negros e indígenas, é um guarda-chuva que aporta movimentos LGBT e feminista também, dando possibilidade de emergência do tema em discussões em sala. P5 destacou que o tema surgia na fala das alunas, não é o professor que iniciava o debate. E surgia em um viés comparativo sobre a desigualdade, "como uma espécie de extensão do que ocorre com o negro, com o indígena”.

P5: Então, aí por 'movimento sociais' tem um guarda-chuva, embaixo do qual a gente tem uma série de lutas, isso inclui, sem dúvidas, a questão de gênero, do movimento LGBT, mas, na ementa da disciplina, o foco está nos movimentos sociais, especificamente, do movimento negro e do movimento indígena. [...] muitas vezes os alunos falam de temas relativos a gênero, a sexualidade, durante a aula, e sentem que há uma conexão e eles mesmos constroem conhecimento para fazer essas transversalidades [...]

$\boldsymbol{E}:$ E, quando esse tema do gênero aparece, como aparece? Você lembra de algum exemplo de como eles trazem isso?

P5: Então, é muito sutil. [...] Quando isso ocorre, quando eles mencionam, isso tá relacionado como uma espécie de extensão do que ocorre com o negro, com o indígena. Eu acho muito curioso porque isso vem deles, estender isso à questão de LGBT, da mulher, eu acho isso interessante, porque isso já vem deles. A gente tava falando sobre o racismo, a colega fez questão de incluir a homofobia, acho isso muito interessante, quer dizer, não era o tema do curso, da aula, não trabalhamos nenhum material específico, mas o aluno trouxe "discriminação" e ativou não só a questão racial, a questão étnica, mas ativou também a questão de gênero.

Em outra perspectiva, o coordenador C6 explicou que o tema entra através dele mesmo, através de sua presença enquanto professor LGBT. Segundo ele, seu próprio corpo é currículo. $\mathrm{O}$ conflito, neste caso, se dá pelo estranhamento com a diferença. O conflito funciona como uma alavanca da discussão, cujo acontecimento pressupõe docentes sensíveis ao tratamento da temática (BASTOS, 2015, p. 129). É a partir do acontecimento conflituoso que o tema entra em cena e vira tópico debatido em sala. Observei também ao longo das entrevistas que o conflito sobre questões de gênero e sexualidade surge muito atravessado por outras categorias, como religião e classe. 
$\boldsymbol{E}:$ Então esse tema não aparece muito, né?

C6: Aparece quando eu dou aula.

E: Por que? Me conta.

C6: Porque eu sou gay!

E: Ah. E como aparece?

C6: Aparece que eu me autossacaneio o tempo inteiro, né? E eu não sou muito de levantar bandeira não, de levantar bandeira de LGBTQ... aquele monte de letra, não. Mas eu acho que as coisas têm que ser naturais. Então, quando eu trago isso para os alunos dentro da sala de aula, logo no primeiro dia de aula, que falo que eu sou casado, que importei um marido, que tava muito queimado no Brasil. [risos] E a gente sai para o campo. Então, eles têm um contato mais íntimo comigo, a gente vai brincar juntos, a gente vai beber juntos, a gente vai beber uma cerveja, a gente cai na água, eu vou na praia com eles. Então, assim, eu acho que, eu acho que é uma forma de ajudar a pessoa a enxergar como sendo diferente "Ah, é assim? Gay é assim? Que bom". [...] E eu já tive o feedback de pessoas falando para mim "Ah, foi legal, comecei a enxergar de uma outra forma". Eu tive muito esse feedback quando eu fui dar aula no [instituto técnico público], por talvez ser uma área mais pobre, em Nova Iguaçu, eu acho que tinha mais gente evangélica e tinha muita gente que vinha conversar comigo sobre isso.

C2 declara que o curso não tinha o tema em uma disciplina, ele aparecia transversalizado. Porém, em sua fala, notei situações de conflitos. Destaco três. A primeira, ao declarar que é uma questão polêmica, C2 usa o advérbio de intensidade "muito" quatro vezes. A segunda, ao dizer que "a gente mostra desde o início é que nós não somos preconceituosos". Mas se as cientistas não fossem realmente preconceituosas seria necessário se educar para que não sejam? Ainda, ao dizer que "o cientista não é" e "o professor não deve ser", por que a marcação verbal diferenciada para as duas funções? $O$ que faz da função científica nãopreconceituosa em si e o que faz da função docente potencialmente preconceituosa a ponto de precisar de prescrição? A terceira, sobre os banheiros. A discussão em torno dos banheiros apontou para uma profunda dificuldade de se conviver com a diferença. A resposta é individualizar os banheiros, não promover a diversidade nesses espaços. C2 explica implicitamente que o tema entra através do espaço, através das marcações de gênero que conferimos às coisas, aos objetos, às estruturas físicas. Assim, o próprio espaço físico da instituição é currículo. 
DOI: http://doi.org/10.46667/renbio.v14i1.550

C2: É um item do conteúdo para ser professor. [...] É uma questão muito muito muito... muito... polêmica. Mas aqui o que a gente mostra desde o início é que nós não somos preconceituosos. O cientista não é preconceituoso. $O$ professor não pode ser preconceituoso. [...] Então, a gente deixa isso bem claro. Agora, existem as questões de usar banheiro, o mesmo banheiro ou não. Isso é uma polêmica que os alunos adoram falar.

E: E como que aparece essa polêmica?

C2: Eu acho que aí parte de cada um. Você não gostaria que um homem se dissesse de repente homossexual usasse o teu banheiro. Acho que tem que ter um banheiro pra cada um, até porque ele não se sente bem também. Não é uma questão de exclusão. É uma questão de liberdade. Os banheiros individuais acho que são os melhores [risos] pra qualquer lugar pra evitar esse tipo de problema. [...] Aqui são banheiros individuais. Na Biologia. Entendeu?

Ainda projetando a justificativa sobre o desenho da pesquisa, surgiu um outro caminho possível no trato de gênero e sexualidade na formação: o pedido da instituição para que se desenvolva disciplina específica dentro da temática. Nesses casos, a professora desenvolveu a disciplina ou o tema na disciplina a partir de um pedido específico da coordenação.

C7: Eu acho que é dele lá da Faculdade de Educação, e eu que pedi que ele desse aqui, que abrisse uma turma para alunos da Biologia. Porque isso aí é uma coisa que a gente vai precisar abordar em algum momento, a gente vai precisar abordar, porque isso é uma orientação do governo federal, a gente precisa cumprir as regras [...].

Quanto ao tema estar presente no currículo, as declarações se dividiram em: não está, está em eletivas, está dentro de uma disciplina, e está transversalizado. Aquelas que responderam não estar presente parecem não reconhecer as discussões mais recentes do campo do gênero e da sexualidade, que os enxergam enquanto dispositivos nas relações pedagógicas. Esses espaços olham para gênero e sexualidade apenas como tópicos de conteúdo. Entendo o currículo em uma perspectiva pós-crítica, produtiva e performática (LOURO, 2005). Dessa forma, a todo instante, mesmo de maneira não explícita ou refletida, esses espaços (in)formavam para práticas e comportamentos em gênero e sexualidade. Assim, aquelas que responderam estar transversalizado pareceram acertar na visão de gênero e sexualidade enquanto dispositivos, como trouxe P5.

P5: [...] Porque o nosso debate ocidental, contemporâneo, ela é transversal o tempo todo. Eu acho que isso é um alinhamento que nós não superamos ainda, e talvez não devamos superar, ela é transversal mesmo. Na minha opinião a sexualidade é transversal, ela está presente o tempo todo. Como você coloca na última frase aqui, é multidisciplinar, ela já é transversal, e acho que a qualidade dela está em ser transversal, a possibilidade de ler um determinado fato ou acontecimento por um outro registro, que é mais da complexidade, eu acho que isso seria mais interessante, é minha opinião. 
DOI: http://doi.org/10.46667/renbio.v14i1.550

Por outro lado, essa opção resvala no perigo de silenciamento e invisibilização do tema (FERRARI, 2011). Por exemplo, C1 explicou que o tema perpassa todo o currículo (Quadro 4). Neste caso, qualquer professora poderia ser indicada para a entrevista, contudo isso não aconteceu (Quadro 3). P3 também confirmou esse ponto, ao dizer que a grande desvantagem da transversalização é que ela não aconteça, "é passar pela sua possibilidade de emergência e não torná-lo visível".

E: Tem a pretensão de que entre alguma disciplina sobre isso?

C1: Então, era o que eu tava pensando, porque... Isso não é uma questão pra gente. Por quê? Vou te dizer porquê. Porque desde que a gente começa a estudar Biologia, a gente conhece todas as formas de expressão dos organismos, não é? É claro que vai ter sempre gente complicada, não é? Mas uma coisa, assim... eu posso estar sendo muito generosa com a minha classe, mas a grossíssimo modo eu acho que a gente é muito libertário nessa questão, porque a visão darwinista, e tudo que a gente aprende, e tudo que a gente vê na natureza, isso realmente não faz parte da da... é uma coisa natural, entendeu? Então, as expressões, os animais que hora tem, os macacos têm, né - mas embora os macacos eles sejam mais hetero do que homo - mas as expressões estão colocadas ali nas manifestações de grupos.

Para P4 o tema do curso limita a transversalização. Tal declaração de P4 aconteceu ao refletir sobre a necessidade de se ter uma disciplina no tema. Ele disse que sim e também discutiu a opção transversalizada. Para ele, o curso de Biologia é muito abrangente, o que dificultaria refletir sobre gênero e sexualidade ao longo dele. Assim, seria importante uma disciplina separada que capacitasse as licenciandas para operar com tais conceitos.

P4: Se ele for bem-organizado, ele pode até ser transversal, mas, por exemplo, na Biologia ele não terá como ser uma coisa transversal. Você tem uma parte sobre animais, zoologia, você tem uma parte sobre botânica, como você vai botar a sexualidade, que é uma coisa humana, relacionada à cultura, às afinidades, até ao psicológico, dentro de botânica? Não tem como se organizar isso. Então eu acho que tem que ser uma coisa em separado.

Além de invisibilização do tema, a transversalização traz o perigo de criação de nichos de discussão que desvirtuariam do tópico principal de discussão, como apontou P3. Ele valorizou o compromisso curricular que as professoras assumem ao se candidatarem para lecionar determinado tópico.

P3: Mas tem que se ter um certo cuidado para o professor não criar a bandeira dele na aula, tem que ter cuidado com isso. Mesmo que o sujeito tenha uma adesão forte ao debate sobre a questão da sexualidade, ou um debate forte sobre as minorias, ele tem que ter um certo cuidado para não tornar a aula o espaço dele de atuação, isso é uma condução política da aula, aí ele está rompendo com uma certa programação, se ele quiser fazer isso, que ele faça isso em espaços extraclasse, ele pode fazer isso de outra forma, em cursos modulares, mas eu acho que a condução curricular tem que seguir uma certa ordem, se não vai romper com isso. 
DOI: http://doi.org/10.46667/renbio.v14i1.550

P7 trouxe também uma reflexão sobre a atuação docente quando se pensa na disciplinarização. No mesmo sentido que $\mathrm{P} 3$, sua preocupação era que a disputa em torno do tema pode levar a diferentes formas de se trabalhar, condicionadas às professoras que ocuparem a vaga. Todavia, ainda que preocupado com o discurso conservador, P7 enxergava potencialidade de produção nessa disputa pelo tema e acreditava ser interessante que as alunas convivessem com diferentes correntes teórico-metodológicas ao longo da formação.

P7: Primeiro, eu tenho o incômodo de dar uma disciplina sobre gênero e sexualidade, não tenho muito consenso comigo mesmo de que isso deveria ser uma disciplina obrigatória nos cursos de graduação, tenho uma certa resistência a achar que deveria ser obrigatória, certamente porque vira de alguém, ela vira um terreno.

P7: A outra desvantagem que eu acho que pode oferecer, eu também ofereceria é que, na medida que isso não é visto como disciplina, isso abre mão para o avanço do conservadorismo, mas me parece que é exatamente que a gente aceita como disciplina que a gente aceita o enfrentamento. Eu acho que a gente tem que apostar em novos modos de luta política, que não são necessariamente pautados na guerra, no enfrentamento, mas na criação de outras possibilidades, que não é necessariamente bater de frente.

Essa limitação da docência universitária existe em outros tópicos? Que estratégias podem ser promovidas nesses espaços que evitem a criação de terrenos? Por que esses terrenos são criados? As professoras universitárias estão sendo capacitadas para se entenderem enquanto professoras, docentes, formadoras ou existe uma lacuna de formação pedagógica para esta profissão?

Sejam disciplinas específicas ou como tema incluído em uma disciplina mais abrangente, todas as professoras entrevistadas apoiavam que as temáticas estejam de forma explícita na grade curricular, como vemos nas falas de P5 abaixo.

E: Você acha que isso deveria estar de forma explícita na formação de professores?

P5: Sem dúvida. Eu acho que deveria estar explícita na lei, e aí as instituições teriam uma espécie de diretriz, como acontece nas relações étnico raciais. [...]

E: E quais são as vantagens que você vê de deixar essa disciplina de forma explícita?

P5: Agrega muito. Eu acho que a nossa formação é limitada. [...] quando a gente tem um tema explícito, e aí você tem uma disciplina de gênero e sexualidade, você tem um profissional para trabalhar isso, porque quem dá essa disciplina de estrutura e funcionamento de ensino é um profissional técnico da educação e que nem sempre tem, apesar de ter uma competência na área educacional, indubitável, nem sempre tem competência na área de gênero e sexualidade, [...] 
DOI: http://doi.org/10.46667/renbio.v14i1.550

Mesmo nos espaços que optaram por incluir os temas de gênero e sexualidade em suas grades curriculares, teremos de lidar com o fato de que isso não garante que a licencianda conseguirá ressignificar sua postura perante as diferenças, como aponta C3.

C3: É a mesma coisa a gente ter uma disciplina de diversidade sexual, que mostre que aquilo tem que ser encarado de uma forma diferente, mas ele não vai se livrar dos seus... das suas concepções que ele adquiriu durante toda a sua vida religiosa, familiar etc. Eu acho que isso ai é muito difícil.

\section{E: $\underline{\text { Mesmo se tivesse a disciplina? }}$}

\section{C3: Mesmo se tivesse. [...]}

Quais saberes as licenciandas já carregam? Isso nos leva de volta a refletir sobre os saberes docentes. O saber docente é "um saber existencial, pois está ligado não somente à experiência de trabalho, mas também à história de vida do professor, ao que ele foi e ao que ele é, o que significa que está incorporado à própria vivência do professor, à sua identidade, ao seu agir" (TARDIF, 2014, p. 110). Para além de eleger um melhor formato, é estar atenta aos investimentos realizados antes, durante e após a formação inicial.

\section{O que é possível concluir?}

Lacunas também formam. Mesmo quando não há disciplinas sobre gênero e sexualidade, há investimento de formação no tema. A ausência de reflexão estruturada curricularmente também é uma opção formativa. Porém, como tentei expor ao longo desse texto, tal escolha faz com que os saberes docentes nesta área fiquem à mercê de experiências pessoais, não se configurando como saberes disciplinares ou pedagógicos. Isso pode contribuir com a fala das professoras da escola de não se sentirem preparadas para o tema, como apontam outras pesquisas (COELHO e CAMPOS, 2012; BASTOS, 2015; JARDIM e BRÊTAS, 2006; BIANCON, 2005).

E quando há disciplinas sobre gênero e sexualidade, o que as leva à possibilidade de aparecimento? As condições de emergência do tema oficializado na formação, a partir do recorte empírico analisado aqui, se apresentam, primeiro, (a) na intenção das coordenadoras de formar práticas reflexivas, isto é, de formar professoras para a Educação Básica com um sólido repertório de conhecimentos e grande habilidade de manejá-los, sendo capaz de operar em situações novas (Maurice TARDIF, 2014). Também (b) pela consolidação de documentos de governo que disputam e inserem o tema nas formações. Entre os materiais consultados para a organização curricular, aquele que parece ter maior participação, a partir da fala das coordenadoras entrevistadas, são os documentos oficiais (leis, diretrizes, resoluções). Os documentos mais recentes, como as diretrizes CNE/CES 02/2015, trazem em seu texto a exigência de se atuar em e para a consolidação dos Direitos Humanos, o que vai ao encontro de formar professoras que atuem pedagogicamente no respeito à diversidade. 
DOI: http://doi.org/10.46667/renbio.v14i1.550

Disciplinares ou transversais, a questão é: que investimentos estão sendo feitos para que as discussões levem a uma reflexão ética e teoricamente embasada dos temas de gênero e sexualidade? Que estratégias a formação pode mobilizar para constituir identidades docentes não discriminatórias? Novas perguntas se desdobram. Encerrar é difícil, mas necessário. Provisoriamente, posso dizer que conhecer a formação de professoras de Biologia é um desafio porque ela não é feita para ser entendida. Mas também não é feita para não ser entendida. Ela é fruto de disputas. Para os temas de gênero e sexualidade não seria diferente. Então, não tem a lógica que nós, como pesquisadoras, gostaríamos que tivesse. É a continuidade dos esforços de análise que vão contornar padrões e nos apontar caminhos.

\section{Referências}

BASTOS, Felipe. "A diretora sabe que você está trabalhando isso na sala de aula?" Diversidade sexual e Ensino de Ciências, 2015, 180 f. Dissertação (Mestrado em Educação) - Pontifícia Universidade Católica do Rio de Janeiro, Rio de Janeiro, 2015.

BIANCON, Mateus L. A educação sexual na escola e as tendências da prática pedagógica dos professores, 2005. Dissertação (Mestrado em Ensino de Ciências e Educação Matemática) - Universidade Estadual de Londrina, 2005.

BRASIL. Resolução CNE/CES 02/2015. Brasília: CNE/CES, 2015.

COELHO, Leando J.; CAMPOS Luciana. M. L. Diversidade sexual e licenciandos em Ciências Biológicas: que professor formamos? Revista SBEnBio, Niterói, v. 5, p. 1-10, 2012.

ELLSWORTH, Elizabeth. Modos de endereçamento: uma coisa de cinema, uma coisa de educação também. In: SILVA, T. T. (Org.). Nunca fomos humanos - nos rastros do sujeito. Belo Horizonte: Autêntica, 2001. p.7-76.

FERRARI, Anderson. Silêncio e silenciamento em torno das homossexualidades masculinas. In:____; MARQUES, L. P. (Org.). Silêncios e educaçãa. Juiz de Fora: UFJF, 2011. p. 91112.

FOUCAULT, Michel. A arqueologia do saber. Lisboa: Edições 70, 2014.

Ditos e escritos, volume IV: estratégia, poder-saber. 3.ed. Rio de Janeiro: Forense Universitária, 2012a.

Ditos e escritos, volume V: ética, sexualidade e política. 3.ed. Rio de Janeiro: Forense Universitária, 2012b.

Vigiar e punir. Nascimento na prisão. Petrópolis: Vozes, 2008.

MANZINI, Eduardo J. Entrevista semiestruturada: análise de objetivos e roteiros. SEMINÁRIO INTERNACIONAL SOBRE PESQUISA E ESTUDOS QUALITATIVOS, 2. 2004. Anais do... Bauru: USC, 2004. 
DOI: http://doi.org/10.46667/renbio.v14i1.550

JAPIASSÚ, Hilton. \& MARCONDES, Danilo. Dicionário básico de filosofia. Rio de Janeiro: Zahar, 2006.

JARDIM, Dulcilene P.; BRÊTAS, José R. S. Orientação sexual na escola: a concepção dos professores de Jandira-SP. Revista Brasileira de Enfermagem, v. 59, n. 2, p. 57-62, 2006.

LOURO, Guacira Lopes. O currículo e as diferenças sexuais e de gênero. In: COSTA, Marisa Vorraber. (Org.). O currículo nos limiares do contemporâneo. 2.ed. Rio de Janeiro: DP\&A, 2005. p. 85-92.

REVEL, Judith. Michel Foucault: conceitos fundamentais. São Carlos: Claraluz, 2005.

SARMENTO, Manuel. J. O estudo de caso etnográfico em educação. In: ZAGO, N. (Org.) Itinerários de pesquisa: perspectivas qualitativas em sociologia da educação. Rio de Janeiro: DP\&A/Lamparina, 2003. p. 137-182.

TARDIF, Maurice. Saberes docentes e formação profissional. 17.ed. Petrópolis, RJ: Vozes, 2014.

Revisão gramatical realizada por: Raquel Pinho

E-mail: raquel.ciencias@gmail.com 